\title{
Spatial and temporal patterns of fish assemblages in mountain streams of the Ren River, southwest China
}

\author{
Fei Liu ${ }^{1}$, Pengcheng $\operatorname{Lin}^{2}$, Huanzhang $\mathrm{Liu}^{3}$, and Jun Wang ${ }^{4}$ \\ ${ }^{1}$ Institute of Hydrobiology Chinese Academy of Sciences \\ ${ }^{2}$ Institute of Hydrobiology, Chinese Academy of Sciences \\ ${ }^{3}$ Affiliation not available \\ ${ }^{4}$ State Key Laboratory of Eco-hydraulic in Northwest Arid Region of China, Xi'an \\ University of Technology
}

February 23, 2021

\begin{abstract}
The spatial-temporal patterns of fish assemblages in lotic systems can provide useful information in developing effective conservation measures. This study aimed to explore the spatiotemporal changes in fish assemblage and their association with environmental factors in mountain streams of Ren River, southwest China. Filed investigations were conducted at 18 sites during rainy and dry season in 2017. A total of 21 species, belonged to 3 orders, 8 families and 19 genera, were collected. Analysis of similarities (ANOSIM) showed fish assemblages structure varied significantly at the spatial scale, but not at the temporal scale. In low order sites, fish assemblages were mainly dominated by cold water and rheophilic species (e.g. Rhynchocypris oxycephalus, Scaphesthes macrolepis, Metahomaloptera omeiensis and Gnathopogon herzensteini), while those in high order sites were predominated by warm water and eurytopicity or stagnophilic species (e.g. Squalidus argentatus, Hemiculter leucisculus and Zacco platypus). Canonical correspondence analysis (CCA) showed fish assemblages were structured by a combination of large-scale landscape factors (e.g. altitude and C-link) and small-scale habitat features (e.g. channel width, water temperature and depth). Among these factors, landscape factors had the greatest influence on fish assemblage, while local habitat measures played less important roles or just acted in certain season.
\end{abstract} Spatial and temporal patterns of fish assemblages in mountain streams of the Ren River,
southwest China

Fei Liu ${ }^{1}$,Pengcheng $\operatorname{Lin}^{1}$, Huanzhang Liu $^{1}$ and Jun Wang ${ }^{2}$

1 The Key Laboratory of Biodiversity and Conservation of Aquatic Organisms, Institute of Hydrobiology, Chinese Academy of Sciences, Wuhan, Hubei Province, 430072, People's Republic of China.

2

State Key Laboratory of Eco-hydraulic in Northwest Arid Region of China, Xi'an University of Technology, Xi'an, Shanxi Province, 710048, People's Republic of China.

Correspondence to: Fei Liu, Institute of Hydrobiology, Chinese Academy of Sciences, No.7 Donghu South Road, Wuhan, Hubei, 430072, People's Republic of China. Email: liufei@ihb.ac.cn.

Abstract

The spatial-temporal patterns of fish assemblages in lotic systems can provide useful information in developing effective conservation measures. This study aimed to explore the spatiotemporal changes in fish assemblage and their association with environmental factors in mountain streams of Ren River, southwest 
China. Filed investigations were conducted at 18 sites during rainy and dry season in 2017. A total of 21 species, belonged to 3 orders, 8 families and 19 genera, were collected. Analysis of similarities (ANOSIM) showed fish assemblages structure varied significantly at the spatial scale, but not at the temporal scale. In low order sites, fish assemblages were mainly dominated by cold water and rheophilic species (e.g., Rhynchocypris oxycephalus, Scaphesthes macrolepis, Metahomaloptera omeiensis and Gnathopogon herzensteini ), while those in high order sites were predominated by warm water and eurytopicity or stagnophilic species (e.g., Squalidus argentatus ,Hemiculter leucisculus and Zacco platypus ). Canonical correspondence analysis (CCA) showed fish assemblages were structured by a combination of large-scale landscape factors (e.g., altitude and C-link) and small-scale habitat features (e.g., channel width, water temperature and depth). Among these factors, landscape factors had the greatest influence on fish assemblage, while local habitat measures played less important roles or just acted in certain season.

\section{Keywords}

Spatial-temporal changes / Fish assemblage / Mountain stream / Fish conservation

\section{Introduction}

Understanding how fish assemblages are structured in lotic ecosystems is one of the interesting aspects of community ecology and these knowledges can provide useful information in diversity conservation and ecological restoration (Araújo et al. 2009). The River Continuum Concept (RCC) suggested longitudinal variations in physicochemical environment (e.g., width, depth, velocity, flow volume and temperature) influence structural and functional characteristics of lotic aquatic communities (Vannote et al. 1980). Species diversity often increase with the upstream-downstream gradient, responding to the increased habitat diversity and food availability (Lowe-McConnell 1975). Although the original RCC developed for aquatic macroinvertebrates, similar patterns have been found for fish assemblages in both temperate and tropical regions (Hughes and Gammon 1987; Matthews 1998; Ferreira and Petrere Jr. 2009). Subsequent studies further found that large-scale landscape position, such as stream order, stream size, link magnitude, confluence link (C-link) and downstream link (D-link), are important factors in structuring stream fish assemblage (Fausch et al. 1984; Osborne and Wiley 1992; Fairchild et al. 1998; Smith and Kraft 2005; Mullen et al. 2011). For example, Fausch et al (1984) found fish assemblages changed gradually with stream order. Smith and Kraft (2005) demonstrated that confluence link and stream order were the stream network position measures with the greatest influence on fish assemblages. Osborne and Wiley (1992) observed downstream link explained the greatest portion of the variance in fish species richness and suggested downstream processes significantly influence the structure of fish assemblages. In addition, seasonal variations in environmental conditions caused by periodic flooding are expected to have significant impacts on stream fish assemblages (Ostrand and Wilde 2002; He et al. 2017). Flooding can increase the diversity and availability of habitat structures and food resources, and then lead to changes in fish assemblage between dry and wet seasons (Araújo et al. 2009). Therefore, the current consensus is that stream fish assemblages are structured by a series of local and regional factors operating at multiple spatial and temporal scales (Matthews 1998; Jackson et al. 2001; Vardakas et al. 2015). However, the relative importance of these factors varies with environmental variability, climate conditions, and nature of fish assemblage in the survey area (Grossman et al. 1998; Jackson et al. 2001).

To date, spatial and temporal variations of stream fish assemblages have been tested in numerous regions, including the North America (Ostrand and Wilde 2002; Mullen et al. 2011), Latin America (Silvano et al. 2000; Habit et al. 2007; Araújo et al. 2009; Fernandes et al. 2013), Europe (Pires et al. 1999; Vardakas et al. 2015) and South Asia (Bhat 2004). In recent years, similar studies have been also conducted in China. However, nearly all these studies were concentrated in the central and eastern regions (Yan et al. 2010; Li et al. 2012; He et al. 2017; Zhu et al. 2017). The southwest China, where raises the greatest number of streams and rivers and supports the highest degree of fish diversity, received little attention.

The Dabashan Mountains is located at the border area of Hubei province, Chongqing municipality, Sichuan province and Shanxi province in the southwest China. It is an important water source for many river systems. 
The Jialing River and the Han River, which represent the largest tributaries of the upper and middle Yangtze river respectively, both originate from this region. Furthermore, the Dabashan Mountains harbors a high level of biodiversity and species endemicity, which has been listed as one of the 35 biodiversity conservation priority area of China (Ministry of Ecology and Environment of People's Republic of China 2010). Therefore, the Dabashan Mountains plays important roles in water security and biodiversity conservation. Even so, little information about the distribution patterns of fish fauna in this region is available until now. On the other hand, fish diversity in this region has been decreased seriously due to the increased human activities, such as over-fishing, hydropower station construction and water pollution (Zeng 1991). The development of effective conservation strategies needs urgently to understand the organization mechanisms of fish assemblages in this area.

Therefore, fish fauna and environmental features in mountain streams of the Ren River, the largest tributaries of the upper Han River, were investigated in this study. The main objective was to test whether and how fish assemblages in this mountain river vary at different spatial and temporal scales. Furthermore, we would like to identify the key environmental factors that contributed most to the observed spatial-temporal patterns of fish assemblage structure. We believe these studies can help us to understanding how fish assemblage structured in such mountain river systems and then provide valuable information in future fish conservation and management.

\section{METHODS}

\subsection{Study area}

The Ren River is the largest tributaries of the upper Han River, which originates from the Dayanshan Mountain in the southern foot of the Dabashan Mountains. It flows for $211.4 \mathrm{~km}$ before drain into the Han River in Ziyang County, Shanxi Province, with a drainage basin of $4871 \mathrm{~km}^{2}$. The whole basin is located in the center of the Chongqing Dabashan National Nature Reserve, which aim to protect the subtropical forest ecosystems and their biodiversity.

In this study, fish fauna and habitat features were investigated in the upper Ren river, a $128 \mathrm{~km}$ stretch ranging from headwater to the confluence with Pingba River (Fig. 1). There are many medium to small streams (e.g., Kang river, Huangxi River, Shixi River, Lanxi River, Caiziba River, Longtan River, and Yanzi River) flow into this stretch. The climate is typical subtropical monsoon, with hot-wet summers and colddry winters. The annual average temperature is 13.8 and the monthly mean temperature changes from 24.8 (July) to approximately 2.4 (January). The average annual rainfall is $1261.4 \mathrm{~mm}$, but is unevenly distributed in time, with $68 \%$ of total annual precipitation occurs in May to September. The river habitat is characterized by mainly deep valleys, shallow and winding channels, rapid water flow. As the headwaters and most tributaries originate from primeval forest with less human influence, water quality in this area preserves well, except for a few sites due to urban sewage and industrial wastewater.

\subsection{Fish sampling}

Fish surveys were conducted in May-July and December 2017, representing the rainy and dry season, respectively. A total of 18 sites were sampled, covering the length of the main channel of the Ren Rive and its main tributaries. Among them, 8 sites located at 1st-order streams, 6 at 2nd-order, 5 at 3rd-order, and 1 at 4 th-order streams (Table 1). The sampling sites were selected based on accessible, similarity in habitat types, and to maximize the diversity of habitat types (Araujo et al. 2009). Fish specimens were caught by a backpack electro-fisher (Susan 1030S, China; $12 \mathrm{~V}$ import, $250 \mathrm{~V}$ export) by single pass. Each sampling was carried out at different habitat units (riffles, glides and pools) by two persons against the current. The length of each segment varied between 100 and $200 \mathrm{~m}$, according to the accessibility. After samplings, all captured specimens were identified to species level, measured $(\mathrm{mm})$ and weighted $(\mathrm{g})$. Individuals that could be confidently identified were released downstream from the sites after recovery, while individuals that could not be identified in the field were fixed in buffered formaldehyde (7\%) and then transported to the laboratory for further taxonomic determination. 
For each site, habitat parameters were measured prior to fish sampling. Specially, water temperature (), $\mathrm{pH}$, dissolved oxygen $(\mathrm{mg} / \mathrm{l})$ and conductivity $(\mu \mathrm{s} / \mathrm{cm})$ were measured using an YSI6680 Multi Probe. Average channel width $(\mathrm{m})$ was calculated using a Ranger Laser Finder instrument in the beginning, middle and end of the sampling reach. Water depth was measured at three points $(25,50$, and $75 \%$ of the transect width) along each transect. Current velocity $(\mathrm{m} / \mathrm{s})$ was determined in the middle of the sampling site with a LJD-10 flow-meter. Substratum composition was categorized to bedrock, cobble, pebble/gravel, sand and mud/silt, according to Hoeinghaus et al (2007). In addition, landscape parameters were recorded in situ or calculated from topographical maps (Table 1). Therein, altitude, longitude and altitude (m) were recorded by a Garmin GPS-76 system at the time of field sampling. Stream order was assigned according to Strahler (1957). Description and calculation of stream link magnitude (link, Shreve, 1966), C-link (Fairchild et al. 1998), and D-link (Osborne and Wiley 1992) were adapted from Smith and Kraft (2005). Measures of these spatial parameters referenced to a public map of Chengkou County (1:50 000).

\subsection{Data analysis}

Non-metric multidimensional scaling (NMDS) ordination analysis based on the Bray-Curtis similarity matrix (Clarke 1993), were used to classify the spatial (stream order) and temporal (season) variations of fish assemblage structure. Relative abundance data for each species was $\log (\mathrm{x}+1)$ transformed to normalize the data and avoid skew. Bray-Curtis similarity coefficient was calculated based on the relative abundance matrices. Rare species that occurred in less than 3 sites were excluded from the analysis. Next, one-way analysis of similarity (ANOSIM) was carried out to determine whether fish assemblages changed significantly among stream orders or seasons. Then, a similarity of percentage analysis (SIMPER) was used to identify species that contributed most to the spatial or temporal dissimilarities of fish assemblages. All these analyses were performed with the PRIMER 5 software package (Clarke and Warwick 2001), including modules "NMDS", "SIMPER" and "ANOSIM".

Difference in environmental factors between seasons were tested by one-way analysis of variance (ANOVAs) using SPSS statistical programs (Version 20.0). Relationships between fish assemblage structure and environmental factors for each season were examined by constrained canonical ordinations. Detrended Correspondence Analysis (DCA) were used to determine the appropriate model for direct gradient analysis (Leps and Smilauer 2003). As the length of gradients for the first axis was estimated at 1.908 ( 33 ) for wet season and 1.746 ( 33 ) for dry season, Redundancy Analysis (RDA) was applied in further analyses. Fish relative abundance data were $\log _{10}(\mathrm{x}+1)$ transformed and the downweighting option was used to reduce the influence of rare species. Environmental variables that did not meet the normality assumption (Shapiro-Wilk test, $\mathrm{p}<0.05$ ) were transformed using natural logarithms, and collinear environmental viable with high variation inflation factors (VIF $>20$ ) were eliminated from further analyses (McCune and Grace 2002). Stepwise forward selection with Monte Carlo permutation tests (999 permutations, $\mathrm{p}<0.05$ ) was used to select a parsimonious set of explanatory variables. These analyses were performed using the software CANOCO for Windows 4.5 version (Ter Braak and Smilauer 2002).

\section{Results}

\subsection{Species composition}

A total of 1330 individuals, represented by 21 fish species, were collected during the sampling period (Table 2). These species were belonged to 3 orders, 8 families and 19 genera. Of these,Leptobotia hansuiensis were endemic to upper Han River drainage,Scaphesthes macrolepis and Schizothorax prenanti have been assessed as vulnerable by the China Species Red List (Jiang et al., 2016). Cypriniformes was the most abundant order, represented by 17 species and accounted for $91.0 \%$ of the total species, followed by Perciformes (3 species) and Siluriformes (1 species). Cyprinidae was the major dominated family, represented by 13 species and accounted for $61.9 \%$ of the total species. The remaining families comprised only one to three species.

The most common and abundant species was Rhynchocypris oxycephalus, which occurred in $71.7 \%$ of the sampling occasions and accounted for $50.3 \%$ of the total number of specimens captured. The next most abundant species was Gnathopogon herzensteini, which accounted of $9.6 \%$ the total number of specimens, 
followed by Metahomaloptera omeiensis (9.4\%), S. macrolepis (8.5\%), and Zacco platypus (5.3\%). Some species, such asHemibarbus maculates, Pseudogobio vaillanti, Spinibarbus sinensis and S. prenanti, just occurred occasionally.

\subsection{Spatial and temporal variations in fish assemblage structure}

Fish assemblage structure varied significantly at the spatial scale. NMDS ordination plot showed that sampling sites at 3rd-order stream were mainly gathered to the lower left of the graph, while those of 4th-order sites were clustered to the right (Fig. 2). ANOSIM confirmed that the fish assemblages differed significantly among stream orders (Global $\mathrm{R}=0.156, \mathrm{p}=0.034 \mathrm{j} 0.05$ ). According to the SIMPER analysis, fish assemblages in the Ren River basin were highly dominated by cold-water or rheophilic species, such as $R$. oxycephalus ,S. macrolepi, M. omeiensis and G. herzensteini, except for the 4th-order sites (Table 3). Specially, fish assemblages in 1st-order sites were typified by $R$. oxycephalus, contributing $95.7 \%$ of the similarity. Fish assemblages in 2nd-order were typified by R. oxycephalus and G. herzensteini, contributing $78.3 \%$ and $7.1 \%$ of the similarity, respectively. Fish assemblages in 3rd-order sites were typified by $R$. oxycephalus, $M$. omeiensis and S. macrolepi, contributing $55.4 \%, 28.1 \%$ and $9.3 \%$ of the similarity, respectively. From 1 storder sites to 3th-order sites, the abundance of $R$. oxycephalus decreased gradually, while the abundance of M. omeiensis and S. macrolepi increased continuously. By contrast, fish assemblages in 4th-order sites were predominated mainly by warm-water and lentic or eurytopic species, such as Squalidus argentatus ,Hemiculter leucisculus and Z. platypus .

However, there was no significantly seasonal change in fish assemblages. NMDS ordination plot revealed substantial overlap between fish assemblages in wet and dry season (Fig. 3). ANOSIM further confirmed that the fish assemblages did not show significant changes across seasons (Global $\mathrm{R}=-0.022, \mathrm{p}=0.745 i_{0.05}$ ).

\subsection{Relationships between fish assemblage and environmental factors}

Latitude of the 18 sampling sites ranged from $456 \mathrm{~m}$ to $1290 \mathrm{~m}$. Stream orders ranged from 1st to 4th. Link, C-link and D-link ranged from 1 to 20, 1 to 13 and 2 to 30, respectively (Table 1). ANOVA analysis showed that water temperature, $\mathrm{pH}$, dissolved oxygen, conductivity, velocity and the percent of cobble varied significantly with seasons (Table 4). Specially, water temperature in wet season was significantly higher than that in dry season, while $\mathrm{pH}$, dissolved oxygen, conductivity, velocity and the percent of cobble showed the opposite trend. Other variables showed no significant seasonal changes.

After the forward selection procedure, 3 environmental variables (i.e., altitude, C-link and channel width) were finally retained for the wet season, while 5 environmental variables (i.e., altitude, C-link, channel width, water temperature and depth) were retained for the dry season.

For the wet season, altitude explained the most variance (44.5\%), followed by C-link (33.6\%) and width $(15.9 \%)$. The species-environment correlations of the first two ordination axes were 0.924 and 0.526 , respectively. The first ordination axis accounted for $45.6 \%$ of the variance of the species data, which the second axis $50.6 \%$ of this variance. Altitude $(-0.911)$ and C-link (-0.779) were negatively correlated with the first axis, while channel width $(0.529)$ positively corrected.

For the dry season, altitude explained the most variance (37.1\%), followed by C-link (24.0\%), width (20.0\%), water temperature $(15.7 \%)$ and depth $(14.7 \%)$. The species-environment correlations of the first two ordination axes were 0.946 and 0.591 , respectively. The first ordination axis accounted for $39.6 \%$ of the variance of the species data, which the second axis $46.3 \%$ of this variance. Altitude $(-0.915)$ and C-link (-0.709) were negatively correlated with the first axis, while channel width (0.620), water temperature $(0.587)$ and depth (0.514) positively corrected.

The RDA ordination plots showed that $R$. oxycephalus was positively related to altitude and negatively related to channel width in both seasons (Fig. 4 and Fig. 5). S. macrolepis was positively related to C-link in both seasons. However, the species-environment association of other species, such as S. argentatus, $Z$. platypus, G. herzensteini, M. omeiensis, Cobitis sinensis and Rhinogobius giurinus, showed some changes across seasons. In wet season, all these species were positively related to channel width (Fig. 4). But in dry 
season, some species (e.g., Z. platypus, G. herzensteini, C. sinensis and R. giurinus ) preferred to habitats with high water temperature and some species (e.g., M. omeiensis ) tended to deep water (Fig. 5).

\section{Discussion}

\subsection{Spatial and temporal patterns of fish assemblage}

Several studies have observed significant spatial and temporal variations in fish assemblages in natural streams (Silvano et al. 2000; Fernandes et al. 2013; He et al. 2017). Specially, spatial variations in fish assemblage were usually caused by habitat features changes along the longitudinal gradient, while seasonal variability in fish assemblages were often attributed to flooding-related changes in habitat characteristics and induced seasonal migrations of fish species (Silvano et al. 2000; Fernandes et al. 2013; He et al. 2017).

The present study revealed that fish assemblages in streams of Ren River basin varied significantly with stream order. However, no significant changes in fish assemblages were observed between seasons. These results were consistence with other studies (Habit et al. 2007; Yan et al. 2010; Li et al. 2012; Zhu et al. 2017; Fernandes et al. 2013). For example, Ostrand and Wilde (2002) found spatial components of variation in fish assemblages in the upper Brazos River were greater than seasonal components. Fernandes et al (2013) revealed fish assemblages in Meridional Amazonian streams changed among watersheds (spatial variation), but not seasonally (temporal variation). Fish assemblages in Northwestern Great Plains streams varied more spatially than temporally (Mullen et al. 2011). Similar findings were also observed in the lower Yangtze River, China (Yan et al. 2010; Li et al. 2012; Zhu et al. 2017). Yan et al (2010) observed that fish assemblages in Puxi Stream were significantly different in spatial variation but not in temporal variation. Li et al (2012) found that fish assemblages in a mountain stream of the north Tiaoxi River differed along the stream continuum, but there was little apparent change associated with the seasons. These studies together suggested that seasonal variations in habitat features may not always lead to temporal changes in fish assemblage structure. One of the possible reasons is the structure of fish assemblages in these stream systems were determined more by average or persistent spatial heterogeneity in environmental conditions and environmental variability than by seasonal variation in environmental conditions (Ostrand and Wilde 2002; Mullen et al. 2011; Li et al. 2012).

In this study, some habitat variables (e.g., water temperature, $\mathrm{pH}$, dissolved oxygen, conductivity, velocity and substrate composition) changed markedly from wet season to dry season. However, temporal changes in these habitat variables were probably exceeded by deterministic landscape variations along the longitudinal gradient. As a result, fish assemblages were determined mainly by large-scale spatial variables (e.g., altitude and C-link), while local habitat variables played less important roles or just acted in single season. In addition, fish assemblages in the Ren River basin were dominated mainly by resident fish species, such as $R$.oxycephalus , $G$. herzensteini, M. omeiensis ,S. macrolepis and Z. platypus . These species were welladapted to the instream running water and did not depend on long-distance migration to complete their life cycles. Therefore, the lack of seasonal change in fish assemblages in streams of the Ren River was probably resulted from the natural variability of the river system and the sedentary life habit of fish species.

\subsection{Environmental effects on fish assemblage}

The present study showed fish assemblages in streams of the Ren River basin were structured by a combination of large-scale landscape factors (e.g., altitude and C-link) and local habitat features (e.g., channel width, water temperature and depth). Among which, landscape factors acted as the most important contributor in both wet and dry season. The importance of landscape position in structuring fish assemblages have been demonstrated by numerous studies (e.g., Fairchild et al. 1998; Smith and Kraft 2005; Li et al. 2012; He et al. 2017; Zhu et al. 2017). According to landscape perspective, streams should be regarded as connected networks with a definable "network geometry", rather than a linear hierarchy most represented by stream order (Benda et al. 2004; Smith and Kraft 2005). Abiotic and biotic stream characteristics changed from low-order headwater streams to high-order downstream locations (Fausch et al. 1984; Smith and Kraft 2005). Specially, high altitude and low-order stream often refer to low water temperature, narrow channel, shallow water and low immigration (Murugavel and Pandian 2000.). Therefore, landscape position in stream network 
geometry can influence the distribution patterns of fish species and thus assemblage structure (Smith and Kraft 2005; Li et al. 2012). In this study, $R$.oxycephalus, a typical cold-water species, was restricted to headwaters and small tributaries with higher elevation, and absent from the lower locations. By contrast, species that adapted to warm-water and lentic environment (e.g., S. argentatus and H. leucisculus ) were distributed exclusively in the lower locations. The barrier caused by the extreme and harsh environmental conditions in high altitudes seems effectively prevented the dispersion and colonization of these fish species from lowland (Li et al. 2012).

Compared to above-mentioned landscape spatial factors, local habitat factors (e.g., channel width, water temperature and depth) played less important roles in determining fish assemblage in the Ren River basin. However, the influence of these factors increased somewhat in the dry season. In the wet season, water temperature and resource availabilities were not the limiting factors for warm-water fish species, such as $S$. argentatus, H. leucisculus and Z. platypus, because they were high enough to satisfy the ecological requirements of these species. However, As the water level and water temperature declined in winter, diversity and availability of habitat and food resources became limited (Liu et al. 2019). In this situation, these species tended to occupy larger and deeper habitats where possess warmer water temperature and richer food resources ( $\mathrm{Li}$ et al. 2012).

\subsection{Implications for conservation}

This study was the first to describe the spatial-temporal variation of fish assemblages in mountain streams in the southwest China. Information obtained from this study will enhance our understanding of the variation in fish assemblages, and then help to develop strategies for future fish diversity protection in such mountain streams. A total of 21 fish species were collected during the sampling period. Among which, S. macrolepis and $S$. prenanti have been considered as vulnerable. These species used to be important commercial targets in Ren River basin. However, compared to history records, their distribution range has shrunk significantly, and their population size has declined seriously (Zeng 1991). In addition, the miniaturization tendency of these two species has become evident (Zeng 1991). The survive prospect of $S$. prenanti is gloomier, as only three specimens of were collected during our study period. Overfishing might be the main reason responsible for this phenomenon (Zeng 1991). To protect these vulnerable species, the local government should strengthen fishery management and fight against illegal strictly. In addition, the present study indicated that fish assemblages in streams of the Ren River basin were influenced mainly by landscape factors, such as altitude and C-link. Specially, $R$. oxycephalus, a representative cold-water species, was restricted to headwaters and small tributaries with higher elevation. This species is an excellent bioindicator species low-temperature water and a good model species for studying freshwater fish biogeographic, because of their typically low dispersal ability and restriction to small mountain habitats (Yu et al. 2014). Climate change and anthropogenic interferences have seriously threatened this species (Yu et al. 2014). Therefore, to maintain the stability of fish assemblage structure in such stream ecosystems, human activities that will destroy the naturality and connectivity of stream habitat, such as deforestation, dredging and damming, should be forbidden strictly.

Acknowledgements This study was supported by the National Natural Science Foundation of China (31400359), Natural Science Foundation of Shanxi (2018JQ5121) and Sino BON-Inland Water Fish Diversity Observation Network. The authors are grateful to Lixia Shi, Zhi Zhang, Liangxia Su, Nenghan Wang, Jian Zhang and Chunsen XU for their help in filed samplings.

\section{Conflict of Interest}

The authors declare no conflict of interest.

\section{Data Accessibility Statement}

Fish and environmental variable data were deposited in the Dryad Digital Repository,https://doi.org/10.5061/dryad.jq2bvq886. Other relevant data can be accessed in the manuscripts. 
Fei Liu https://orcid.org/0000-0003-4404-0971

\section{References}

Araújo FG, Pinto BCT, Teixeira TP. 2009. Longitudinal patterns of fish assemblages in a large tropical river in southeastern Brazil: evaluating environmental influences and some concepts in river ecology. Hydrobiologia 618: 89-107.

Benda L, Poff NL, Miller D, Dunne T, Reeves G, Pess G, Pollock M. 2004. The network dynamics hypothesis: how channel networks structure riverine habitats. Bioscience 54: 413-427.

Bhat A. 2004. Patterns in the distribution of freshwater fishes in the rivers of Central Western Ghats, India and their association with environmental gradients. Hydrobiologia 529: 83-97.

Clarke KR. 1993. Non-parametric multivariate analyses of changes in community structure. Australian Journal of Ecology 18: 117-143.

Clarke KR, Warwick RM. 2001. Changes in marine communities: an approach to statistical analysis and interpretation (2nd edition). PRIMPER-E: Plymouth.

Fairchild GW, Horwitz RJ, Nieman DA, Boyer MR, Knorr DF. 1998. Spatial variation and historical change in fish assemblages of the Schuylkill River drainage, southeast Pennsylvania. American Midland Naturalist 139: $282-295$.

Fausch KD, Karr JR, Yant PR. 1984. Regional application of an index of biotic integrity based on stream fish communities. Transactions of the American Fisheries Society 113: 39-55.

Fernandes IM, Lourenco LS, Ota RP, Moreira MMM, Zawadzki CH. 2013. Effects of local and regional factors on the fish assemblage structure in Meridional Amazonian streams. Environmental Biology of Fish 96: 837-848.

Ferreira FC, Petrere Jr. M. 2009. The fish zonation of the Itanhaém river basin in the Atlantic Forest of southeast Brazil. Hydrobiologia 636: 11-34.

Grossman GD, Ratajczak J, Robert E. Crawford M, Freeman MC. 1998. Assemblage organization in stream fishes: effects of environmental variation and interspecific interactions. Ecological Monographs 68: 395-420.

Habit E, Belk M, Victoriano P, Jaque E. 2007. Spatiotemporal distribution patterns and conservation of fish assemblages in a Chilean coastal river. Biodiversity and Conservation 16: 3179-3191.

He DK, Kang ZJ, Tao J, Liu CL, Yang J, Chen YF. 2017. Hydrologic connectivity driven natural stream fish assemblages in mountain streams in the Yangtze River basin: implications for stream fish conservation in monsoonal East Asia. Hydrobiologia 785: 185-206.

Hoeinghaus DJ, Winemiller KO, Birnbaum JS. 2007. Local and regional determinants of stream fish assemblage structure: inferences based on taxonomic vs. functional groups. Journal of Biogeography 34: 324-338.

Hughes RM, Gammon JR. 1987. Longitudinal changes in fish assemblages and water quality in the Willamette River, Oregon. Transactions of the American Fisheries Society 116: 196-209.

Jackson DA, Peres-Neto PR, Olden JD. 2001. What controls who is where in freshwater fish communities the roles of biotic, abiotic, and spatial factors. Canadian Journal of Fisheries and Aquatic Sciences 58: 157-170.

Jiang ZG, Jiang JP, Wang YZ, Zhang E, Zhang YY, Li LL, Xie F, Cai B, Cao L, Zheng GM, Dong L, Zhang ZW, Ding P, Luo ZH, Ding CQ, Ma ZJ, Tang SH, Cao WX, Li CW, Hu HJ, Ma Y, Wu Y, Wang YX, Zhou KY, Liu SY, Chen YY, Li JT, Feng ZJ, Wang Y, Wang B, Li C, Song XL, Cai L, Zang CX, Zeng Y, Meng ZB, Fang HX, Ping XG. 2016. Red list of China's vertebrates. Biodiversity Science 24: 500-551.

Leps J, Smilauer P. 2003. Multivariate Analysis of Ecological Data Using CANOCO. University of Cambridge Press, London. 
Li J, Huang L, Zou L, Kano Y, Sato T, Yahara T. 2012. Spatial and temporal variation of fish assemblages and their associations to habitat variables in a mountain stream of north Tiaoxi River, China. Environmental Biology of Fishes 93: 403-417.

Liu F, Wang JW, Liu HZ, Wang WJ. 2019. Seasonal variations in food resource partitioning among four sympatric gudgeon species in the upper Yangtze River, China. Ecology and Evolution 9: 7227-7236.

Lowe-McConnell RH. 1975. Fish Communities in Tropical Freshwaters: Their Distribution, Ecology, and Evolution. Longman. Quarterly Review of Biology 192: 672-673.

Matthews WJ. 1998. Patterns in freshwater fish ecology. Chapman and Hall, London.

McCune B, Grace JB. 2002. Analysis of Ecological Communities. MjM Software Design. Glenenden Beach, Oregon.

Ministry of Ecology and Environment of People's Republic of China. 2010. China national biodiversity conservation strategy and action plan. http://www.mee.gov.cn/gkml/hbb/bwj/201009/t20100921_194841.htm

Mullen JA, Bramblett RG, Guy CS, Zale AV, Roberts DW. 2011. Determinants of fish assemblage structure in Northwestern Great Plains streams. Transactions of the American Fisheries Society 140: 271-281.

Murugavel P, Pandian TJ. 2000. Effect of altitude on hydrology, productivity and species richness in Kodayar - a tropical peninsular Indian aquatic system. Hydrobiologia 430: 33-57.

Osborne LL, Wiley MJ. 1992. Influence of tributary spatial position on the structure of warmwater fish assemblages. Canadian Journal of Fisheries and Aquatic Sciences 49: 671-681.

Ostrand KG, Wilde DR. 2002. Seasonal and spatial variation in a prairie stream-fish assemblage. Ecology of Freshwater Fish 11: 137-149.

Pires AM, Cowx IG, Coelho MM. 1999. Seasonal changes in fish community structure of intermittent streams in the middle reaches of the Guadiana basin, Portugal. Journal of Fish Biology 54: 235-249.

Shreve RL. 1966. Statistical law of stream numbers. Journal of Geology 74: 17-37.

Silvano RAM, Amaralc BD, Oyakawad OT. 2000. Spatial and temporal patterns of diversity and distribution of the Upper Juruá River fish community (Brazilian Amazon). Environmental Biology of Fishes 57: 25-35.

Smith TA, Kraft CE. 2005. Stream fish assemblages in relation to landscape position and local habitat variables. Transactions of the American Fisheries Society 134: 430-440.

Strahler AN.1957. Quantitative analysis of watershed geomorphology. Eos, Transactions American Geophysical Union 38: 913-920.

Ter Braak CJF, Smilauer P. 2002. CANOCO Reference Manual and Cano-draw for Windows User's Guide: Software for Canonical Community Ordination (Version 4.5). Microcomputer Power, New York.

Vannote RL, Minshall GW, Cummins KW, Seddel JR, Cushing CE. 1980. The river continuum concept. Canadian Journal of Fisheries and Aquatic Sciences 37: 130-137.

Vardakas L, Kalogianni E, Zogaris S, Koutsikos N, Vavalidis T, Koutsoubas D, Skoulikidis NH. 2015. Distribution patterns of fish assemblage structure in an Eastern Mediterranean intermittent river. Knowledge and Management of Aquatic Ecosystems 416: 30.

Yan YZ, Chu L, Xiang XY, Jia YJ, Tao J, Chen YF. 2010. Spatial and temporal variation of fish assemblages in a subtropical small stream of the Huangshan Mountain. Current Zoology 56: 670-677.

Yu D, Chen M, Tang QY, Li XJ, Liu HZ. 2014. Geological events and Pliocene climate fluctuations explain the phylogeographical pattern of the cold water fish Rhynchocypris oxycephalus (Cypriniformes: Cyprinidae) in China. BMC Evolutionary Biology 14: 225. 
Zeng MH. 1991. Fish and Fishery in the upper Ren River. In: Fish resources and utilization protection in rivers of Sichuan (eds Sichuan Agricultural Division Committee, editorial committee of 《Fish resources and utilization protection in rivers of Sichuan》), pp. 140-144. Sichuan Science and Technology Press, Chengdu.

Zhu R, Li Q, Wang WJ, Chu L, Yan YZ. 2017. Effects of local, river-network and catchment factors on fish assemblages in the headwater streams of the Xin'an basin, China. Journal of Freshwater Ecology 32: 300-313.

\section{Figures}

Figure1 Sketch map of the sampling sites in the upper Ren River.

Figure 2 NMDS ordination plot of spatial (stream orders) changes in fish assemblage structure in mountain streams of the Ren River based on the Bray-Curtis similarity of fish species.

Figure 3 NMDS ordination plot of seasonal changes of fish assemblage structure in mountain streams of the Ren River based on the Bray-Curtis similarity of fish species.

Figure 4 RDA ordination plots showing relationship between fish assemblage and environmental variables in the Ren River basin during wet season.

Figure 5 RDA ordination plots showing relationship between fish assemblage and environmental variables in the Ren River basin during dry season.

\section{Tables}

Table 1 Spatial parameters of samplings sites in mountain streams of the Ren River.

Table 2 Total number $(\mathrm{N})$, percent number $(\mathrm{N} \%)$, weight $(\mathrm{W}, \mathrm{g})$, percent weight $(\mathrm{W} \%)$ and percent frequency of occurrence of fish species in mountain streams of the Ren River.

Table 3 Typifying species determined by SIMPER analysis for fish assemblages in different stream orders in the Ren River.

Table 4 Mean value and standard errors of different habitat variables at 18 sites in the Ren River.

Table 1 Spatial parameters of samplings sites in mountain streams of the Ren River

\begin{tabular}{|c|c|c|c|c|c|c|c|}
\hline Site code & Latitude & Longitude & Altitude $(\mathrm{m})$ & S- order & Link & C-Link & D-Link \\
\hline$\overline{\mathrm{S} 1}$ & $\mathrm{E} 109^{\circ} 11^{\prime} 07.1^{\prime \prime}$ & $\mathrm{N} 31^{\circ} 47^{\prime} 35.6^{\prime \prime}$ & 1274 & 1 & 1 & 13 & 2 \\
\hline $\mathrm{S} 2$ & $\mathrm{E} 109^{\circ} 07^{\prime} 02.1^{\prime \prime}$ & $\mathrm{N} 31^{\circ} 43^{\prime} 30.7^{\prime \prime}$ & 1290 & 1 & 1 & 13 & 2 \\
\hline S3 & $\mathrm{E} 109^{\circ} 04^{\prime} 15.5^{\prime \prime}$ & $\mathrm{N} 31^{\circ} 48^{\prime} 32.3^{\prime \prime}$ & 1074 & 2 & 3 & 11 & 5 \\
\hline S4 & $\mathrm{E} 109^{\circ} 01^{\prime} 56.0^{\prime \prime}$ & $\mathrm{N} 31^{\circ} 49^{\prime} 02.3^{\prime \prime}$ & 991 & 3 & 5 & 11 & 6 \\
\hline S5 & $\mathrm{E} 108^{\circ} 56^{\prime} 07.2^{\prime \prime}$ & N31 $51^{\circ} 37.1^{\prime \prime}$ & 891 & 2 & 3 & 9 & 9 \\
\hline S6 & $\mathrm{E} 108^{\circ} 51^{\prime} 47.3^{\prime \prime}$ & $\mathrm{N} 31^{\circ} 48^{\prime} 52.6^{\prime \prime}$ & 899 & 1 & 1 & 8 & 10 \\
\hline S7 & $\mathrm{E} 108^{\circ} 52^{\prime} 26.1^{\prime \prime}$ & N31 $53 ' 50.1^{\prime \prime}$ & 1022 & 2 & 2 & 7 & 12 \\
\hline S8 & $\mathrm{E} 108^{\circ} 48^{\prime} 49.2^{\prime \prime}$ & $\mathrm{N} 31^{\circ} 47^{\prime} 46.9^{\prime \prime}$ & 1040 & 1 & 1 & 6 & 13 \\
\hline S9 & $\mathrm{E} 108^{\circ} 42^{\prime} 20.3^{\prime \prime}$ & N31 $55^{\circ} 07.7^{\prime \prime}$ & 755 & 3 & 13 & 6 & 17 \\
\hline S10 & $\mathrm{E} 108^{\circ} 45^{\prime} 51.4^{\prime \prime}$ & N31 $57^{\circ} 57.1^{\prime \prime}$ & 1083 & 2 & 2 & 6 & 4 \\
\hline S11 & E108 $40^{\prime} 12.4^{\prime \prime}$ & $\mathrm{N} 32^{\circ} 03^{\prime} 48.1^{\prime \prime}$ & 1252 & 1 & 1 & 6 & 2 \\
\hline S12 & $\mathrm{E} 108^{\circ} 39^{\prime} 02.2^{\prime \prime}$ & N31 $58^{\prime} 56.7^{\prime \prime}$ & 777 & 3 & 4 & 5 & 21 \\
\hline S13 & E108 $31^{\prime} 11.3 "$ & $\mathrm{~N} 32^{\circ} 03^{\prime} 51.2^{\prime \prime}$ & 654 & 1 & 1 & 4 & 22 \\
\hline S14 & E108 $25^{\prime} 42.6^{\prime \prime}$ & N32 $06^{\prime} 24.4^{\prime \prime}$ & 456 & 4 & 20 & 3 & 25 \\
\hline S15 & E108 28'09.7" & $\mathrm{N} 32^{\circ} 10^{\prime} 07.2^{\prime \prime}$ & 947 & 1 & 1 & 2 & 29 \\
\hline S16 & E108 $33^{\prime} 49.3^{\prime \prime}$ & N31 $58^{\prime} 29.6^{\prime \prime}$ & 652 & 1 & 1 & 2 & 3 \\
\hline S17 & E108 $32^{\prime} 11.9 "$ & N31'57'34.1" & 642 & 2 & 2 & 2 & 3 \\
\hline S18 & E108 $26^{\prime} 34.5^{\prime \prime}$ & $\mathrm{N} 32^{\circ} 02^{\prime} 49.1^{\prime \prime}$ & 470 & 2 & 3 & 1 & 30 \\
\hline
\end{tabular}


Table 2 Total number $(N)$, percent number $(N \%)$, weight $(W, \mathrm{~g})$, percent weight $(\mathrm{W} \%)$ and percent frequency of occurrence of fish species in mountain streams of the Ren River

\begin{tabular}{llllll}
\hline Species & Number $(N)$ & $N \%$ & Weight $(W)$ & $W \%$ & $F O \%$ \\
\hline Cyprinidae & & & & & \\
Zacco platypus & 70 & 5.26 & 341.2 & 4.11 & 22.64 \\
Opsariichthys bidens & 5 & 0.38 & 47.3 & 0.57 & 5.66 \\
Rhynchocypris oxycephalus & 669 & 50.30 & 2484.3 & 29.90 & 71.70 \\
Hemiculter leucisculus & 57 & 4.29 & 683.0 & 8.22 & 3.77 \\
Hemibarbus labeo & 18 & 1.35 & 19.0 & 19.04 & 5.66 \\
Hemibarbus maculates & 1 & 0.08 & 0.9 & 0.01 & 1.89 \\
Gnathopogon herzensteini & 128 & 9.62 & 751.9 & 9.05 & 41.51 \\
Squalidus argentatus & 47 & 3.53 & 311.3 & 3.75 & 9.43 \\
Platysmacheilus nudiventris & 4 & 0.30 & 27.8 & 0.33 & 3.77 \\
Pseudogobio vaillanti & 7 & 0.53 & 152.1 & 1.83 & 1.89 \\
Scaphesthes macrolepis & 113 & 8.50 & 1279.8 & 15.40 & 30.19 \\
Spinibarbus sinensis & 3 & 0.23 & 2.4 & 0.03 & 1.89 \\
Schizothorax prenanti & 3 & 0.23 & 144.9 & 1.74 & 3.77 \\
Noemacheilidae & & & & & \\
Paracobitis ariegates & 6 & 0.45 & 29.8 & 0.35 & 7.55 \\
$\begin{array}{l}\text { Botiidae } \\
\text { Leptobotia hansuiensis }\end{array}$ & 14 & 1.05 & 29.4 & 0.35 & 3.77 \\
Cobitidae & & & & & \\
Cobitis sinensis & 20 & 1.50 & 84.3 & 1.01 & 15.09 \\
$\begin{array}{l}\text { Balitoridae } \\
\text { Metahomaloptera omeiensis }\end{array}$ & 125 & 9.40 & 152.6 & 1.84 & 43.40 \\
Bagridae & & & & & \\
Leiocassis crassilabris & 3 & 0.23 & 26.2 & 0.32 & 3.77 \\
$\begin{array}{l}\text { Percichthyidae } \\
\text { Siniperca scherzeri }\end{array}$ & 9 & 0.68 & 137.1 & 1.65 & 3.77 \\
$\begin{array}{l}\text { Gobiidae } \\
\text { Rhinogobius giurinus }\end{array}$ & 24 & 1.80 & 38.5 & 0.42 & 13.21 \\
Rhinogobius cliffordpopei & 4 & 0.30 & 5.3 & 0.06 & 3.77 \\
\hline
\end{tabular}

Table 3 Typifying species determined by SIMPER analysis for fish assemblages in different stream orders in the Ren River

\begin{tabular}{lllll}
\hline Stream order & Species & Average abundance (\%) & Average similarity (\%) & Contribution \% \\
\hline 1st & P. oxycephalus & 69.5 & 47.3 & 95.7 \\
2nd & P. oxycephalus & 53.8 & 28.3 & 78.3 \\
\multirow{3}{*}{ 3rd } & G. herzensteini & 15.4 & 2.6 & 7.1 \\
& P. oxycephalus & 35.2 & 22.4 & 55.4 \\
& M. omeiensis & 24.0 & 22.1 & 28.1 \\
4th & S. macrolepis & 16.4 & 3.8 & 9.3 \\
& S. argentatus & 27.1 & 26.4 & 54.1 \\
& H.leucisculus & 3.6 & 9.4 & 19.3 \\
& Z. platypus & 7.5 & 5.6 & 11.4 \\
& G. herzensteini & 20.5 & 3.3 & 6.8 \\
\hline
\end{tabular}


Note. Only species that contribute to more than $5 \%$ of the average similarity within group were shown.

Table 4 Mean value and standard errors of different habitat variables at 18 sites in the Ren River

\begin{tabular}{lllll}
\hline Habitat variables & Wet season & Dry season & $F$-ratio & $p$-value \\
\hline Water temperature () & $23.3 \pm 2.2$ & $12.1 \pm 1.4$ & 4962.836 & 0.000 \\
pH & $7.5 \pm 0.7$ & $9.0 \pm 0.3$ & 627.012 & 0.000 \\
Dissolved oxygen $(\mathrm{mg} / \mathrm{s})$ & $7.7 \pm 1.0$ & $10.4 \pm 1.4$ & 420.589 & 0.000 \\
Conductivity $(\mu \mathrm{s} / \mathrm{cm})$ & $244.8 \pm 72.7$ & $269.7 \pm 107.6$ & 385.900 & 0.000 \\
Velocity (m/s) & $0.8 \pm 0.3$ & $0.5 \pm 0.2$ & 5.603 & 0.028 \\
width (m) & $5.4 \pm 3.2$ & $4.4 \pm 2.9$ & 3.830 & 0.052 \\
depth (m) & $0.7 \pm 0.3$ & $0.5 \pm 0.2$ & 3.916 & 0.063 \\
Bedrock\% & $43.9 \pm 14.6$ & $42.5 \pm 15.7$ & 0.586 & 0.444 \\
Cobble\% & $28.6 \pm 7.4$ & $30.3 \pm 9.2$ & 28.048 & 0.000 \\
Pebble\% & $20.0 \pm 9.5$ & $19.7 \pm 9.5$ & 0.120 & 0.729 \\
Sand\% & $4.2 \pm 4.6$ & $7.2 \pm 4.3$ & 0.355 & 0.552 \\
Silt \% & $0.4 \pm 0.3$ & $0.3 \pm 1.2$ & 0.295 & 0.593 \\
\hline
\end{tabular}

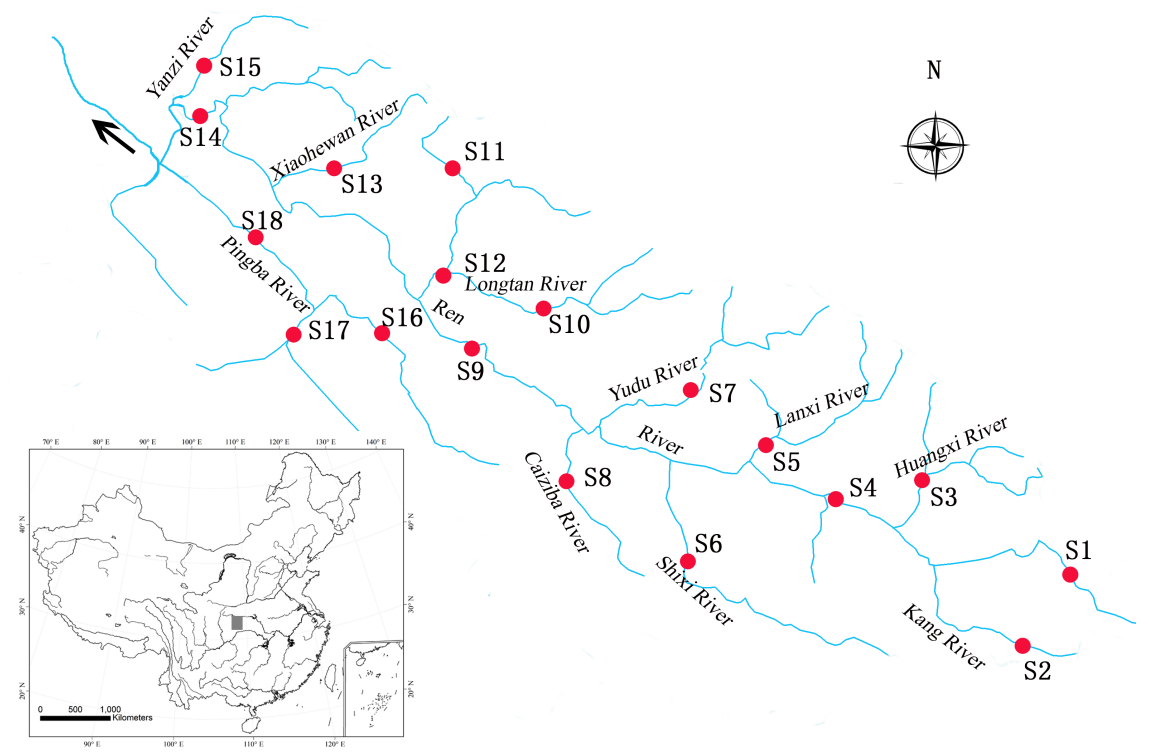




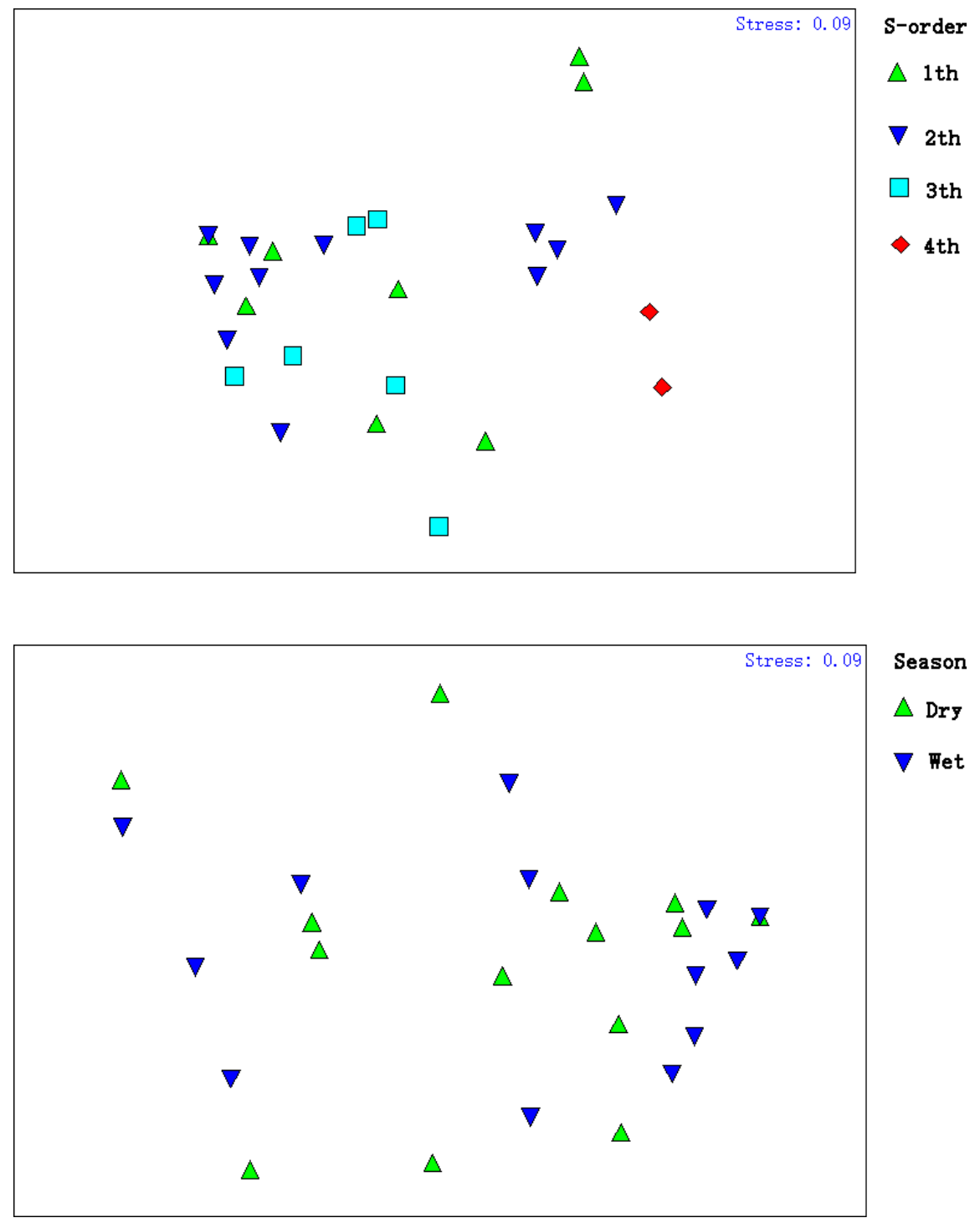




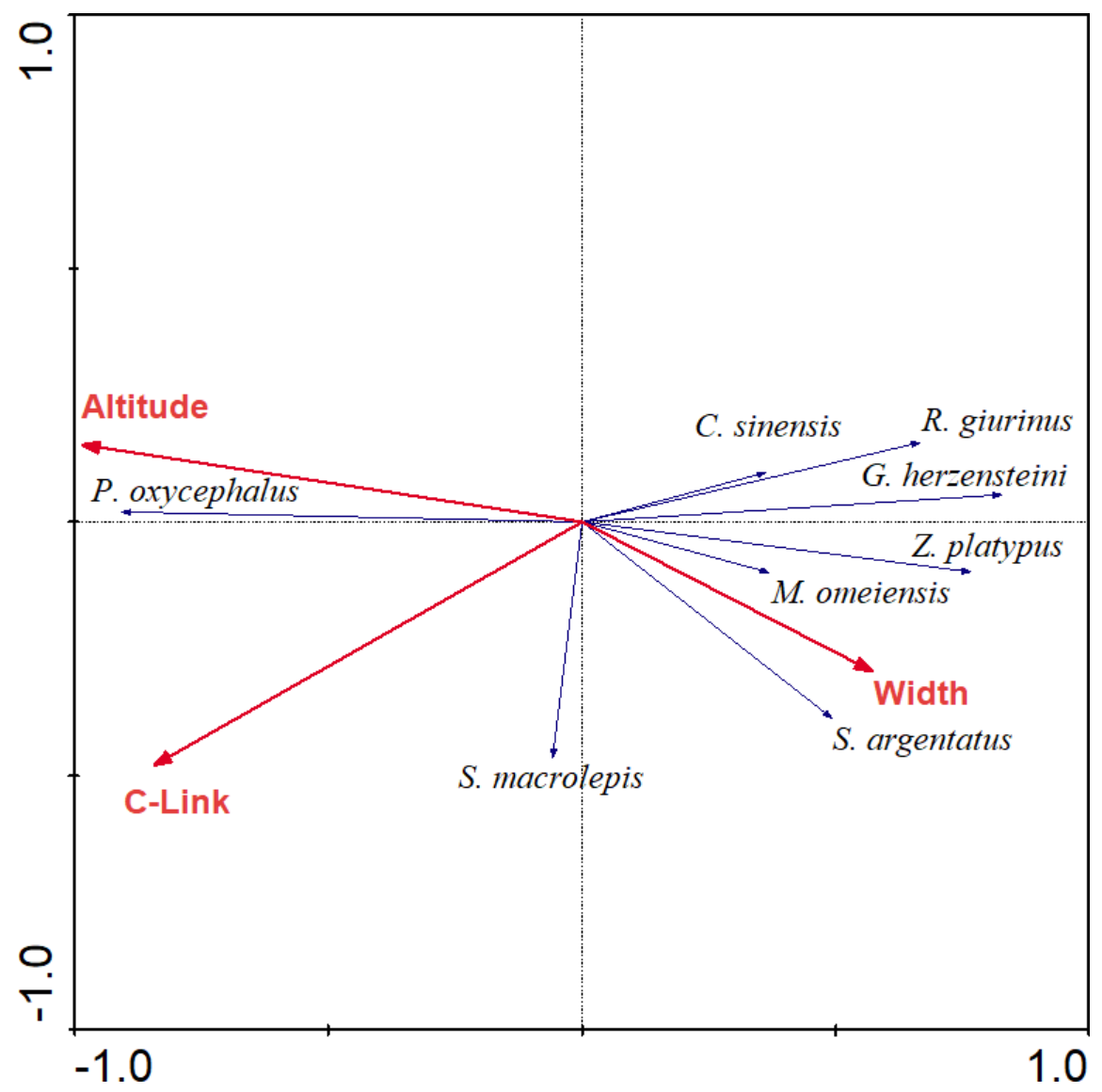




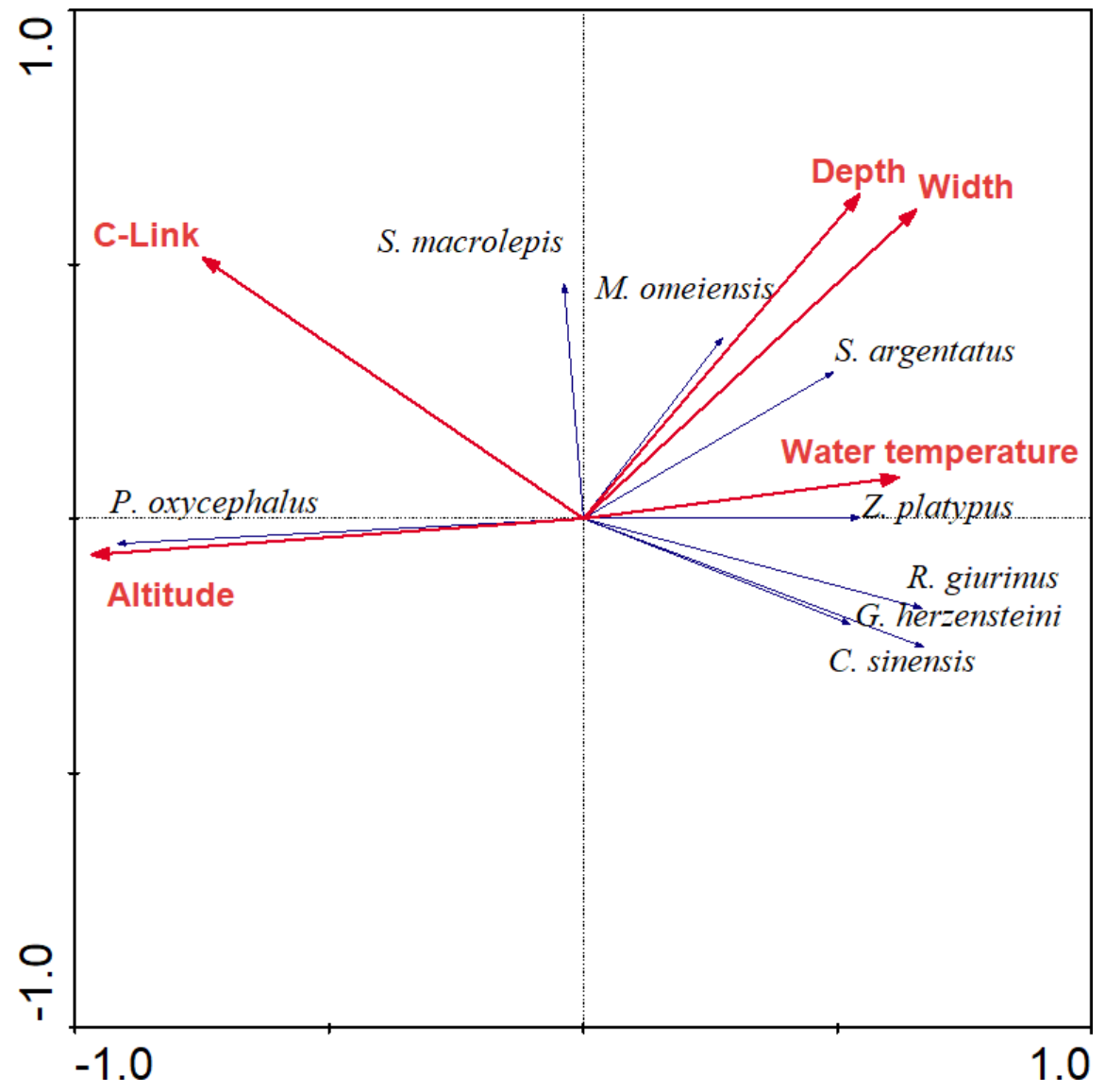

